\title{
As Plantas, os Solos, os Metais e a Vida Jogos Múltiplos ${ }^{\dagger}$
}

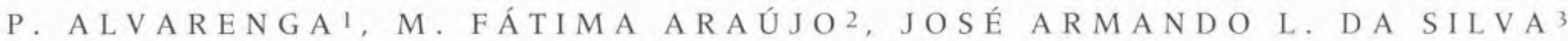

\section{INTRODUÇÃO}

Os efeitos dos metais nas plantas e as formas de defesa destas perante ambientes contaminados são normalmente abordados dum ponto de vista acção-reacção e usualmente não se encara a resposta da planta de um ponto de vista químico. Por isso conceitos como complexação, redução, precipitação, etc. são normalmente esquecidos ou secundarizados em trabalhos que envolvem esse tipo de temática. Neste trabalho procurar-se-á dar relevo a estes e a outros conceitos químicos que se vão, todavia, cruzar com conceitos de origem biológica.

\section{OS METAIS NO SISTEMA SOLO-PLANTA}

Em geral entre os organismos vivos as plantas assumem especificidades nas suas relações com o meio circundante, quando comparadas com os animais, em consequência da sua fixação ao solo.

Algumas plantas têm a particularidade de concentrarem teores elevados de alguns elementos. Por isso, estudos sobre as interacções solo-planta permitem um melhor conhecimento do metabolismo em organismos vivos, quer usando as plantas para recuperar solos com teores elevados em alguns metais, quer por manipulação genética, introduzindo, em espécies não adaptadas a determinado solo, mecanismos de defesa contra um meio impróprio para a sua sobrevivência.

Quando se fala no papel dos metais nas interacções solo-planta, não se está, certamente, a utilizar a definição clássica do metal, que se refere quase exclusivamente às propriedades físicas do seu estado elementar (maleabilidade, ductibilidade, condutividade, etc.), o que é bastante irrelevante para este propósito, sendo neste caso mais adequada a sua classificação funcional. Porém, é necessário levar em linha de conta que esses termos funcionais possuem limitações, sendo bastante imprecisos e utilizados com arbitrariedade conforme o autor. Muitas das categorias sobrepõem-se, tornando difícil escolher o termo certo para utilizar em determinado contexto. Apresentam-se de seguida algumas definições funcionais comuns, utilizadas para classificar metais em estudos bio-ambientais [1]:

Metal essencial - designa-se por metal essencial aquele que é necessário no ciclo de vida completo do organismo, e cuja ausência produz sintomas específicos de deficiência, ultrapassáveis apenas pela administração desse metal, se o elemento faz parte de uma molécula de um constituinte ou metabolito essencial da planta. O efeito do metal no organismo pode ser estudado utilizando uma curva de dose-resposta (Figura 1);

Metal tóxico - todos os metais são tóxicos, mas o grau de toxicidade varia enormemente de metal para metal e de organismo para organismo. A toxicidade, tal como a essencialidade, pode ser definida na forma de uma curva de dose-resposta, correspondendo a toxicidade a doses superiores às usualmente consideradas ideais (Figura 1):

Metal pesado - trata-se de um termo muito impreciso e que pode levantar grandes objecções. É origi- nalmente um termo baseado na densidade do elemento, o que possui um significado a nível biológico pouco significativo; hoje em dia utiliza-se, embora de forma não consensual, para designar metais com número atómico $>20$. É um termo erradamente utilizado com uma conotação pejorativa ligado à poluição e toxicidade, mas que é, por conveniência de utilização, amplamente utilizado por muitos autores;

Metal disponível - as fracções da quantidade total de metal que são solúveis na solução do solo, ou extractáveis para esta sob determinadas condições, são as que contêm o elemento na forma passível de ser assimilado pelo organismo vivo. A quantidade de metal disponível é mais importante para o estado nutricional e para a toxicidade de uma planta do que a quantidade de metal total;

Metal vestigial - um metal que se encontra em baixas concentrações, alguns $\mathrm{mg} / \mathrm{kg}$ ou concentrações inferiores, numa determinada fonte específica, como por exemplo, no solo, na planta.

Micronutriente metálico- metal que é necessário, a nível nutricional, em pequenas quantidades para um determinado organismo.

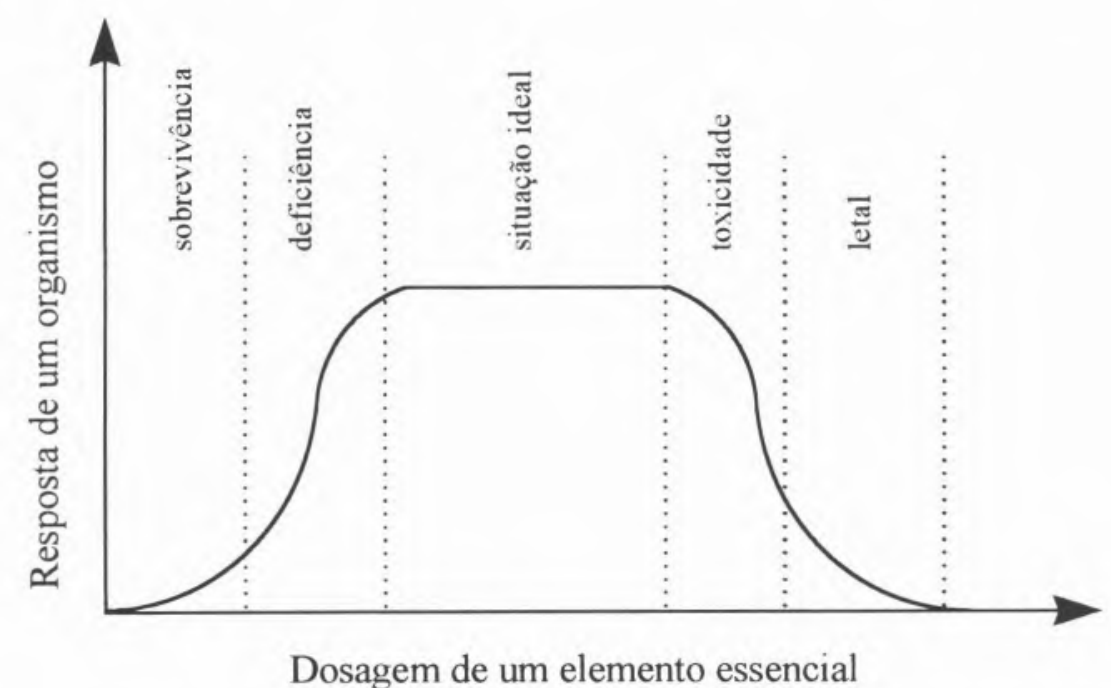

Fig. 1 - Curva de resposta de um organismo em função da dose de metal a que este está exposto [2]. 
Os metais estão presentes nos solos como componentes resultantes de actividades humanas ou como consequência de fenómenos naturais. Várias indústrias, extracção de minérios, exaustão de partículas de gases de motores, centrais de produção de energia, agricultura intensiva, efluentes e resíduos municipais, etc. são actividades humanas que promovem o aumento da concentração de metais no solo. Há que referir, em adição às fontes antropogénicas de metais, que existem disseminadas um pouco por todo o planeta, fontes naturais, como sejam depósitos de minérios e rochas, contendo quantidades relativamente elevadas de metais, os quais, ao longo do tempo, por acção de agentes erosivos se vão disseminando no ambiente.

Porém, um ambiente poluído não significa necessariamente ausência de crescimento de algum tipo de vegetação. A composição elementar das plantas é, no entanto, muito diferente da dos solos em que estas crescem, podendo apresentar ou não alguma relação com ela. Muitas destas diferenças podem ser atribuídas à capacidade que as plantas têm de absorver, de forma diferencial, macroe micro-nutrientes essenciais a partir do solo, entre os quais metais pesados. Baker em 1983 descreveu as plantas como “... mineiras de [nutrientes] da crusta terrestre...", o que é uma expressão muito elucidativa do facto das plantas serem muito selectivas para os nutrientes inorgânicos [3].

A fonte imediata de metais para a planta é a solução do solo. Os metais no ambiente do solo existem como componentes de diferentes fracções: (1) iões metálicos livres ou complexos solúveis desses iões na solução do solo; (2) iões metálicos que ocupam locais de permuta iónica, especificamente adsorvidos em constituintes inorgânicos do solo; (3) metais ligados a compostos orgânicos; (4) metais na forma de compostos precipitados ou insolúveis, nomeadamente óxidos, carbonatos e hidróxidos, e (5) metais na estrutura cristalina de minerais. Os metais contami- nantes no solo originados por fontes antropogénicas encontram-se normalmente na forma (1) - (4). Na Tabela 1 listam-se as principais formas químicas de alguns elementos presentes nos solos em condições ácidas e alcalinas, sendo a ordem da esquerda para a direita relativa a concentração decrescente.

\section{COMPOSIÇÃO INORGÂNICA DAS PLANTAS}

As plantas frescas são constituídas por $80-90 \%$ de água e, da fracção restante, mais de $90 \%$ é composta por C, H e O. Se o material orgânico for removido da planta seca por tados nos tecidos das plantas são considerados essenciais. Alguns podem estar simplesmente a substituir outros, ou então desconhecemos ainda o seu papel. Segundo Hewitt [6] os elementos podem ser classificados em: macronutrientes essenciais, os micronutrientes essenciais e os que são benéficos ou essenciais apenas para algumas espécies (ver Tabela 2).

Os teores encontrados para os organismos em geral, abarcam uma vasta gama de concentrações porque se referem a uma grande variedade de ecossistemas e espécies vegetativas diferentes; por esta razão os intervalos de concentrações normais e tóxicas podem por vezes sobrepor-se [7].

Tabela 1 - Principais formas químicas de alguns elementos traço em soluções de solos ácidos e alcalinos [4]

\begin{tabular}{|c|c|c|}
\hline Metal & Solos ácidos & Solos alcalinos \\
\hline $\operatorname{Mn}(I I)$ & $\mathrm{Mn}^{2+}, \mathrm{MnSO}_{4}, \mathrm{Org}^{*}$ & $\mathrm{Mn}^{2+}, \mathrm{MnSO}_{4}, \mathrm{MnCO}_{3}, \mathrm{MnHCO}_{3}^{+}$ \\
\hline $\mathrm{Ni}(\mathrm{II})$ & $\mathrm{Ni}_{2}+, \mathrm{NiSO} 4, \mathrm{NiHCO}_{3}^{+}, \mathrm{Org}^{*}$ & $\mathrm{NiCO}_{3}, \mathrm{NiHCO}_{3}^{+}, \mathrm{Ni}^{2+}$ \\
\hline $\mathrm{Cu}(\mathrm{II})$ & $\mathrm{Org}^{*}, \mathrm{Cu}^{2+}$ & $\mathrm{CuCO}_{3}, \mathrm{Org}^{*}$ \\
\hline $\operatorname{Zn}(\mathrm{II})$ & $\mathrm{Zn}^{2+}, \mathrm{ZnSO}_{4}$ & $\mathrm{ZnHCO}_{3}, \mathrm{ZnCO}_{3}, \mathrm{Zn}^{2+}, \mathrm{ZnSO}_{4}$ \\
\hline Cd(II) & $\mathrm{Cd}^{2}+, \mathrm{CdSO}_{4}, \mathrm{CdCl}^{+}$ & $\mathrm{Cd}^{2}+, \mathrm{CdCl}^{+}, \mathrm{CdSO}_{4}, \mathrm{CdHCO}_{3}^{+}$ \\
\hline $\mathrm{Pb}(\mathrm{II})$ & $\mathrm{Pb}^{2}+, \mathrm{Org}^{*}, \mathrm{PbHCO}_{3}{ }^{+}$ & $\mathrm{PbCO}_{3}, \mathrm{PbHCO}_{3}{ }^{+}, \mathrm{Pb}\left(\mathrm{CO}_{3}\right)_{2}{ }^{2-}, \mathrm{PbOH}^{+}$ \\
\hline
\end{tabular}

Nota: Org*: Metal complexado com a matéria orgânica do solo.

Tabela 2 - Classificação dos elementos no que se refere à nutrição das plantas $|6|$

$\begin{array}{ll}\text { Macronutrientes essenciais } & \mathrm{K}, \mathrm{Ca}, \mathrm{Mg}, \mathrm{C}, \mathrm{H}, \mathrm{O}, \mathrm{P}, \mathrm{N}, \mathrm{S} \\ \text { Micronutrientes essenciais } & \mathrm{Fe}, \mathrm{Cu}, \mathrm{Mn}, \mathrm{Zn}, \mathrm{Mo}, \mathrm{Co}, \mathrm{V}, \mathrm{Na}, \mathrm{Rb}, \mathrm{B}, \mathrm{Si}, \mathrm{Cl}, \mathrm{I}, \mathrm{Se} \\ \text { Benéficos } & \mathrm{Ni}, \mathrm{Al}, \mathrm{Sr}, \mathrm{Sn}, \mathrm{Cr}, \mathrm{Br}, \mathrm{F}\end{array}$

calcinação, os restantes $1,5 \%$ do peso total da planta fresca representam o seu conteúdo mineral (cinzas). As plantas necessitam de, pelo menos, dez elementos para o seu crescimento saudável: $\mathrm{C}, \mathrm{H}, \mathrm{O}, \mathrm{N}, \mathrm{P}$, $\mathrm{K}, \mathrm{S}, \mathrm{Ca}, \mathrm{Mg}, \mathrm{Fe}$ [5]. Estes elementos, com excepção do $\mathrm{Fe}$, são designados macronutrientes, uma vez que eles são necessários em quantidades relativamente grandes. Quanto ao Fe são apenas necessárias pequenas quantidades, sendo um determinado número de outros elementos necessários em quantidades ainda menores: estes são os micronutrientes.

Nem todos os elementos detec-

\section{PROCESSOS BIOLÓGICOS ASSOCIADOS À ABSORÇÃO E TRANSPORTE DOS METAIS PELA PLANTA}

Apenas três elementos são absorvidos pelas partes aéreas da planta: C, O e H. A raiz é o órgão da planta através do qual entram os nutrientes inorgânicos. Segundo Bowling [8], existem quatro elos na cadeia principal de entrada dos minerais na planta: (1) movimento dos iões (e.g. o $\mathrm{Ca}^{2+}$, o $\mathrm{Mg}^{2+}[9]$ ); ou dos respectivos complexos (e.g. o $\mathrm{Cu}^{2+}$, o $\mathrm{Zn}^{2+}$ [9]) no solo até à raiz; (2) entrada na raiz; (3) transporte ao longo 
da raiz até ao sistema vascular; e (4) transporte do elemento para os diversos órgãos da planta.

Os movimentos dos iões metálicos no solo podem ser efectuados de forma simultânea, tanto por difusão, através da solução do solo, comandada pelo gradiente de concentrações criado pela absorção de iões pela raiz, como por fluxo de massa, da solução do solo, à medida que esta se move para a raiz e é absorvida por esta [10].

Quando a solubilidade dos metais é muito baixa, outros processos podem estar envolvidos, tais como: a sintese de agentes quelantes orgânicos pela raiz e por microrganismos associados [10]; a redução do estado de oxidação dos metais através de enzimas, as metal-redutases, que se encontram na raiz na membrana plasmática [11]; por aumento da solubilidade dos metais por alteração do $\mathrm{pH}$ do solo.

A absorção através da raiz foi discutida por Epstein [12] e Bowling [8]. A camada exterior da raiz, a epiderme, é constituída por extensões. os pêlos radiculares, que possuem um revestimento péctico que permite a adesão de partículas do solo. Os pêlos radiculares aumentam consideravelmente a área de contacto com o solo. Um corte transversal numa raiz é mostrado na Figura 2. A maioria das raízes é composta por células de parênquima, em número elevado e com um arranjo livre, com espaços entre elas, formando o córtex. A parte central da raiz, a medula, contém o sistema vascular que é responsável pelo transporte de alimento, água e minerais através da planta. Estes tecidos contêm o xilema, que conduz a água e as substâncias minerais para as partes aéreas da planta, e o floema, que funciona como um condutor do material orgânico, sintetizado no processo de fotossíntese, das folhas até às raízes. As porções de medula na raiz são rodeadas por uma camada distinta de células - a endoderme que separa a medula do córtex. A rodear as paredes destas células encontra-se uma faixa de material suberizadol$^{1}$, chamada banda de Caspary, que forma uma barreira impermeável à água e a solutos iónicos [13]. Para chegar ao xilema, a água e os solutos dissolvidos devem atravessar uma membrana - a plasmalema- que, provavelmente controla as suas entradas para a planta. Alguns dos iões metálicos que se difundem para dentro da raiz são impedidos de sair pelas cargas negativas nas paredes celulares resultantes de grupos carboxílicos dissociados [5].

Depois dos iões entrarem na raiz eles podem ser aí armazenados ou transportados para as folhas [11]. Os botânicos pensam que as paredes celulares das células da raiz desempenham um papel muito importante na tolerância das plantas a metais tóxicos. Turner [14] descobriu que as paredes celulares da raiz de uma planta tolerante a $\mathrm{Cu}$ e $\mathrm{Zn}$, Agrostis tenuis, possuem uma capacidade de ligação aos catiões metálicos muito superior à das plantas não tolerantes da mesma espécie. Através da ligação dos iões tóxicos nas paredes celulares da raiz restringe-se o transporte do metal na planta, evitando que o metal chegue a locais mais sensíveis da raiz e a outros órgãos. Têm todavia sido sugeridos várias outras substâncias na parede celular, incluindo pectatos, aminoácidos e ácidos carboxílicos, como podendo funcionar como agentes complexantes dos metais [15].

Há evidência de transporte de metais através da raiz por duas vias: (1) absorção passiva pelo apoplasmae (2) absorção activa pelo simplasma? Nas plantas superiores, os catiões da solução do solo movem-se passivamente para dentro da raiz, para o apoplasma. As paredes celulares consistem numa rede de celulose, hemicelulose (incluindo pectina) e glicoproteínas, que possuem cargas negativas originadas pelos grupos carboxílicos $\left(-\mathrm{R}-\mathrm{COO}^{-}\right)$, os quais funcionam como permutadores catiónicos e repulsores de aniões. Os catiōes di- e polivalentes são preferencialmente atraídos para estes locais de permuta catiónica [15].

Para os iões metálicos passarem para o xilema e serem distribuídos pela planta, devem passar através da membrana plasmática, na endoderme, e isto só pode ocorrer por transporte activo, via simplasma. Este fenómeno de transporte activo de iões através da membrana plasmática, por vezes contra o gradiente de concentrações dos solutos, deve ser facilitado por qualquer mecanismo de

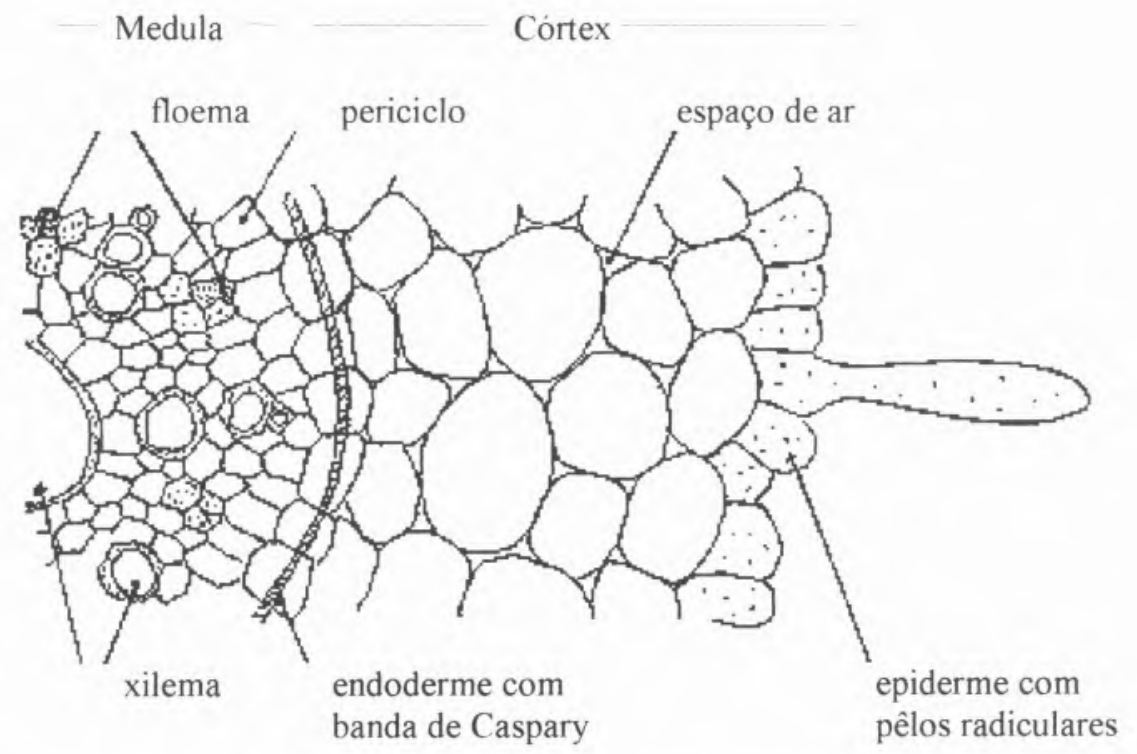

Fig. 2 - Esquema de um corte transversal numa raiz mostrando o córtex e a medula [5] 
transporte que necessita da acção de ionóforos específicos, a natureza dos quais ainda não está bem elucidada. Este mecanismo parece estar dependente do tipo de ião, tamanho, valência e geometria do local de transporte. As espécies químicas dos metais presentes na solução do solo, e disponíveis para absorção, são determinadas pelas condições do solo na vizinhança imediata da raiz, incluindo $\mathrm{pH}$, potencial redox, matéria orgânica do solo, e concentração de outros iões em solução [15].

A Figura 3 ilustra os processos que ocorrem no solo e na planta que contribuem para a biodisponibilidade e absorção de metais pela planta.

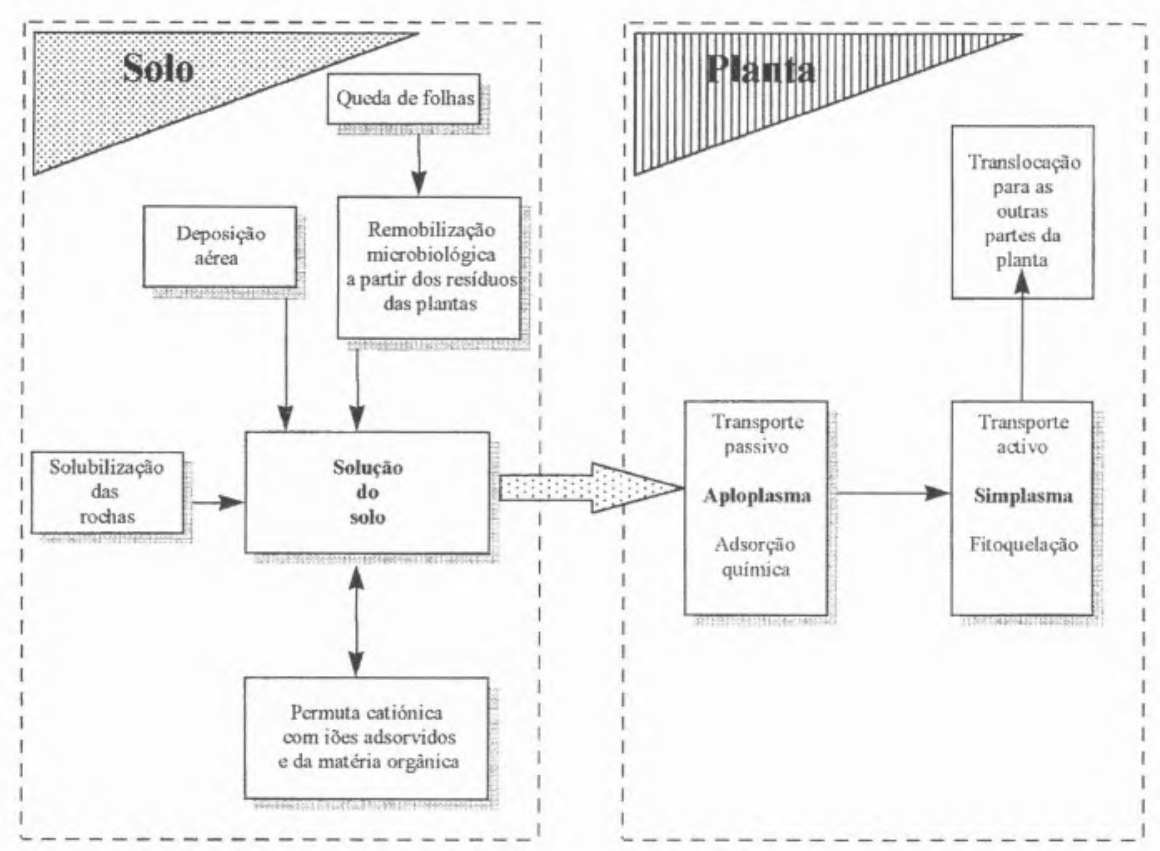

Fig. 3 - Processos que ocorrem no solo e na planta que contribuem para a biodisponibilidade e absorção de metais pela planta [15]

\subsection{Alguns factores que afectam a biodisponibilidade dos metais no solo}

A mobilidade, actividade e biodisponibilidade do metal e dos compostos que ele pode formar podem ser influenciados por um variado nú- mero de factores: pH, temperatura, composição química, condições de oxidação e de redução do solo e interacções entre espécies iónicas [16]. Será através do controle desses factores que se conseguirá aumentar a sua biodisponibilidade.

$\mathrm{O}$ pH é um factor importante para controlar a solubilidade dos metais no solo. Fenómenos de quelação e de adsorção superficiais (em argilas e óxidos hidratados), dependem, entre outros factores, do $\mathrm{pH}$ do solo, e isto por seu turno afecta a disponibilidade de nutrientes e de elementos tóxicos. Alterações do valor de pH por utilização, por exemplo, de fertilizantes permitem conseguir va-

mas não se encontra biodisponível. Um dos exemplos há muito tempo conhecidos é o do ferro, em que alguns factores, como por exemplo o $\mathrm{pH}$ do solo, não permitem a sua absorção pela planta. A estratégia adoptada para corrigir a deficiência neste elemento essencial é a sua adição ao solo com agentes complexantes, como por exemplo o EDTA [17]. Huang et al. [18] demonstraram que a quantidade de $\mathrm{Pb}$ absorvido por plantas cultivadas em solos tratados com agentes complexantes para o chumbo aumentava mais de 260 vezes e por outro lado, estando o $\mathrm{Pb}$ numa forma complexada, é mais inócuo para a planta.

Também é possível, em alguns casos, aumentar a absorção de metais pela planta utilizando-a em combinação com os microrganismos do solo. É sabido que a absorção de certos nutrientes minerais, como sejam o Fe e o Mn, pode ser facilitada pelos microrganismos na rizosfera. Pensa-se que um determinado número de microrganismos, seleccionados em meios de cultura feitos a partir de solos contaminados por metais pesados, podem estimular a absorção de metais por plantas, através de uma série de complexas reaç̧ões bioquímicas de quelação, redução, solubilização, etc.

\section{TOXICIDADE E TOLERÂNCIA}

\subsection{Toxicidade}

Os metais são importantes para a vida saudável da planta, mas o excesso ou a deficiência destes têm efeitos profundos no crescimento e morfologia da mesma. Concentrações excessivas de alguns metais nos solos, que produzem sintomas tóxicos, podem surgir devido a uma variedade de causas naturais ou antropogénicas.

A toxicidade é muitas vezes simplesmente definida como um efeito nocivo num organismo, podendo ser aguda (dose elevada num tempo de exposição curto, normalmente letal), ou crónica (dose pequena durante um longo período de exposição, que pode ser letal ou sub-letal) [15]. 
A toxicidade dos metais nas plantas resulta frequentemente em alterações no aspecto e na morfologia dos frutos, folhas ou raízes, que se demonstram de várias formas. $\mathrm{O}$ efeito tóxico mais comum é a clorose (amarelecimento das folhas por falta de clorofila, seguido por vezes de degenerescência da planta). No entanto, outros sintomas tóxicos podem ser evidentes, principalmente raquitismo (tamanho abaixo do normal) e necrose (aparecimento de manchas negras nos tecidos da planta, que de seguida se desintegram).

A nível celular podem identificar-se vários mecanismos possíveis através dos quais o metal pode causar danos na planta [7,19]: (1) bloqueio de grupos funcionais de moléculas biologicamente importantes, como sejam enzimas, polinucleótidos, ou sistemas de transporte de iões de nutrientes; (2) competição com iões metálicos essenciais de biomoléculas e unidades funcionais celulares; (3) modificação da conformação activa de biomoléculas, especialmente de enzimas e ácidos nucleicos; e (4) rompimento da membrana de células ou de organelos celulares, com perda da sua integridade.

No entanto, é preciso ter presente que "o quanto de efeito tóxico" (ou "que combinação de efeitos tóxicos") é necessário para produzir danos visíveis e sintomas de toxicidade varia de planta para planta, dependendo do tipo de solo, condiçôes ambientais e ecotipo.

\subsection{Tolerância ao metal}

Como alguns metais possuem propriedades muito próximas de outros que lhe são essenciais, a planta pode tornar-se tolerante para aqueles que não são essenciais.

Têm sido propostos vários mecanismos de tolerância para explicar como é que algumas plantas competem com sucesso em condições ambientais tóxicas, sendo capazes de desenvolver ecotipos tolerantes. Os mecanismos de tolerância podem ser divididos em cinco tipos principais [5,7]:

(1) Exsudação de ligandos orgâni- cos pela raiz: as moléculas orgânicas exsudadas pelas células da raiz podem formar quelatos com os metais existentes na rizosfera, tornando-os indisponíveis, ou menos disponíveis, para a absorção pela raiz;

(2) O metal está disponivel para a raiz mas não é captado: neste caso dá-se, por exemplo, uma alteração da parede celular que resulta numa diminuição da permeabilidade ao ião metálico tóxico;

(3) O metal é captado mas é tornado "inofensivo" dentro da planta: neste caso dá-se, por exemplo, a sua deposição na parede celular ou em vacúolos. Para além das moléculas constituintes da parede celular com capacidade de ligação ao metal, como os aminoácidos e proteínas, algumas plantas têm capacidade de produzir polipéptidos especiais, as fitoquelatinas, cuja função é sequestrar o metal e impedir que este fique disponível para o transporte na planta. Também pode ocorrer sequestração em determinados compartimentos da célula, principalmente nos vacúolos. Por exemplo, Brookes et al. [20] descobriram que o $\mathrm{Zn}$ se concentrava no vacúolo da planta Deschampia caespitosa a qual é tolerante ao $\mathrm{Zn}$;

(4) O metal entra mas é seguidamente eliminado: por exemplo, através do fenómeno da exsudação, lixiviação ou queda das folhas;

(5) O metal entra mas o metabolismo é alterado de forma a acomodar quantidades crescentes do metal tóxico: por exemplo, aumentando a quantidade das enzimas inibidas pelo metal.

Há ainda que referir o fenómeno da co-tolerância, mediante o qual, a tolerância a um metal confere tolerância a outros que não se apresentam, no entanto, em concentrações tão elevadas no solo [21].

\section{CLASSIFICAÇÃO DAS PLANTAS EM RELAÇÃO À QUANTIDADE DE METAL ABSORVIDO}

As plantas que permitem o diagnóstico de uma condição ambiental particular são conhecidas como plan- tas indicadoras. O termo qualitativo "espécie indicadora de metal" pode ser usada para descrever espécies que crescem em solos contendo concentrações elevadas de determinados metais. As plantas que crescem em solos com concentrações de metais que são normalmente tóxicas, são tolerantes a esses metais, ou também chamadas metalófitas. Algumas destas plantas excluem os metais tóxicos dos seus tecidos, outras assimilam os metais presentes a um tal grau que podem ser consideradas como acumuladoras de metais. Uma planta acumuladora pode ser definida como tendo uma concentração de metal nos seus tecidos maior do que a encontrada no solo [5].

Segundo Baker [22], a resposta das plantas a níveis crescentes de metais no solo pode reflectir-se de três formas diferentes na concentração do metal nas suas partes aéreas:

(1) Acumuladoras: nas quais o elemento é concentrado nas partes aéreas da planta, sendo retirado do solo quer esteja em baixas ou em elevadas concentraçōes. A razão entre a concentração do elemento na planta e no solo é superior a 1. A concentração do elemento nos tecidos da planta aumenta gradualmente à medida que a concentração no solo aumenta, até que todos os locais da planta estejam ocupados, estabilizando então em determinado valor.

(2) Indicadoras: nas quais a captação e transporte do elemento é regulado de tal forma que a sua concentração na planta reflecte a que existe no solo. As razões de concentração planta/solo são próximas de 1 .

(3) Exclusoras: para as quais a concentração dos elementos nas partes aéreas da planta são mantidas baixas e constantes ao longo de uma vasta gama de concentraçōes do elemento no solo, até um valor crítico, acima do qual o mecanismo de exclusão deixa de ser eficaz. Isto resulta numa entrada e transporte não controlado do elemento para as diversas partes da planta e em fenómenos de toxicidade. Neste tipo de plantas as razões de concentração planta/solo são muito menores que 1 . 
Para além destas três classes de plantas, Brooks et al. [23] identificaram uma forma extrema de acumuladoras, descritas como hiperacumuladoras, para as quais a concentração do metal nos tecidos pode exceder $1000 \mathrm{mg} / \mathrm{kg}$ matéria seca.

São conhecidas plantas acumuladoras de níquel, cobre, manganês, chumbo, zinco e selénio $[3,7,11$, 16,24-27].

\subsection{Mecanismos associados com a acumulação dos metais}

A base bioquímica para a capacidade de acumulação de metais não está ainda bem elucidada. É assumido que a desintoxicação intracelular do metal é conseguida através de ligandos apropriados, com uma grande afinidade para esses metais. Krämer et al. [24] sugerem, por exemplo, que a histidina funciona como quelante do níquel e desempenha um papel importante no transporte do metal da raiz para as folhas, e sua posterior acumulação em plantas do género Alyssum, uma hiperacumuladora de níquel. Por outro lado, a Hybanthus floribundus, uma planta que cresce nalguns solos da Austrália, conhecida como sendo uma acumuladora de níquel (até 1,35\% do peso seco da planta), possui níveis de ácidos dibásicos, principalmente ácido cítrico e ácido málico, que se correlacionam com a concentração de $\mathrm{Ni}$ nas suas folhas. Estes mesmos ácidos aparecem noutras plantas acumuladoras de $\mathrm{Ni}$, pensando-se que formam complexos, solúveis em água, com este catião [5]. O facto do Ni ser mantido na forma solúvel nas partes verdes da planta contribui para a sua eliminação por lixiviação durante a época das chuvas.

Também Farago [5] refere alguns estudos sobre plantas tolerantes a metais, nomeadamente Armeria maritima e Minuarta verna, planta reconhecida como sendo uma indicadora de metal em zonas onde os níveis de $\mathrm{Cu}$ são muito elevados (20000 - $30000 \mathrm{mg} / \mathrm{kg}$ ). Para a A. maritima o $\mathrm{Cu}$ acumula-se na raiz. Por outro lado, observa-se para esta planta um teor muito elevado de prolina na sua raiz, quando comparado com os teores existentes no mesmo tipo de plantas não tolerantes a $\mathrm{Cu}$ colhidas em zonas distintas. Outros estudos citados pela autora referem igualmente que a tolerância a $\mathrm{Cu}$ em algas verdes parece estar associada a certas proteínas que se ligam ao $\mathrm{Cu}$.

As plantas variam muito na quantidade de metais pesados que retiram do solo, quer de espécie para espécie, quer ao longo de vários estádios de crescimento, quer dependendo das condições ambientais [9], apresentando absorções diferentes para o mesmo tipo de metal, consoante as características do solo em que se encontram [28].

\subsection{Significado biológico da acumulação de metais}

Durante muito tempo, a capacidade das plantas para acumular metais foi considerada de forma negativa. Situadas na base de muitas cadeias alimentares naturais, as plantas acumuladoras de metais eram, directa ou indirectamente, responsáveis pela entrada de uma elevada proporção de metais tóxicos nas dietas humana e de alguns animais. Apesar de alguns desses metais serem essenciais para a vida, a sua acumulação excessiva nos organismos vivos é sempre tóxica.

Pouco se sabe acerca do significado biológico e evolucionista da acumulação de metais nas plantas adaptadas a solos naturalmente ricos em metais tóxicos. Existem dados sugerindo que uma das funções da acumulação de determinados metais na planta poderá estar relacionada com a defesa desta contra herbívoros. Assim, Martens et al. [29], demonstraram, numa experiência com uma planta conhecida como hiperacumuladora de $\mathrm{Ni}$ (concentrações superiores a $1000 \mathrm{mg} \mathrm{Ni} / \mathrm{kg}$ matéria seca), a Streptanthus polygaloides, que os insectos herbívoros que se alimentavam de plantas cultivadas em solos sem $\mathrm{Ni}$ sobreviviam, ao passo que os que se alimentavam das plantas cultivadas em solos com Ni mor- riam ou não aumentavam de peso. De todos os parâmetros químicos analisados, apenas a diferença na concentração de Ni entre umas e outras parece explicar este facto.

As espécies selvagens acumuladoras podem dar informações sobre os genes associados ao transporte e acumulação de metais [3]. Os mecanismos de tolerância e de acumulação de metais são ainda pouco conhecidos e pensa-se que envolvem a sua complexação extra- e intracelular, a sua precipitação e a sua compartimentação. Estes conhecimentos associados com o aumento da biodisponibilidade de plantas adequadas podem ser utilizados para a remoção de metais do ambiente, sendo esta tecnologia conhecida por fitorremediação, biorremediação, biorreconversão ou "remediação verde" [11,25].

\section{FITORREMEDIAÇÃO}

Não obstante o número sempre crescente de locais contaminados com metais, os métodos mais comuns para remover os metais pesados em excesso no solo são muito dispendiosos, fazendo com que a sua utilização seja muito limitada. As abordagens correntes para o tratamento de solos contaminados com metais tóxicos são: (1) Remoção de terras: implica a escavação, transporte e deposição de solos contaminados em locais de armazenamento de resíduos perigosos; (2) Fixação: processamento químico dos solos de forma a imobilizar os metais, usualmente seguido pelo tratamento da superfície do solo de maneira a impermeabilizá-la; e (3) Lixiviação: utilização de soluções ácidas, ou com propriedades lixiviantes, de forma a provocar a desadsorção e lixiviação dos metais do solo, seguido pelo recobrimento do local com uma camada de solo limpo $[11,30]$. Qualquer uma destas abordagens envolve grandes orçamentos, com a desvantagem adicional de os próprios métodos de tratamento poderem implicar outras perturbações ambientais, como sejam a perda da actividade biológica dos solos tratados. 
Mais grave ainda do que o tratamento, continua a ser o simples abandono das áreas afectadas, como acontece na maioria das explorações de minas abandonadas, ficando estas áreas expostas a uma lixiviação contínua por efeitos erosivos, aumentando cada vez mais o seu raio de influência.

A capacidade das plantas de acumular quantidades elevadas de elementos pode ser usada como indicador de poluição ambiental específica [31,32], e mesmo ser utilizada na prospecção de minérios [3]: além disso pode servir para a recuperação de solos muito contaminados desde que a espécie escolhida se desenvolva no solo que se pretenda descontaminar [3]. Neste ponto de vista pode ser subdividida em três campos de aplicação: fito-extraç̧ão, fito-estabilização e rizofiltração.

\subsection{Fito-extracção}

A planta óptima para um processo de fito-extracção deve não só tolerar e acumular teores elevados de metais tóxicos nos órgãos que possam ser colhidos (principalmente folhas), como também possuir uma rápida taxa de crescimento e a capacidade de produzir um elevado rendimento em biomassa [3]. Neste processo podem ser utilizadas várias culturas/colheitas sequenciais de plantas acumuladoras de forma a reduzir as concentrações de metais nos solos até níveis aceitáveis para o ambiente. Os resíduos das plantas, secos, calcinados ou compostos, muito ricos em metais tóxicos, podem ser isolados como resíduos perigosos, e tratados como tal, ou então reciclados para lhes serem retirados os metais [25].

Existem muitas vantagens na utilização de plantas acumuladoras de metais na sua remoção de solos contaminados: baixos custos, produção de material vegetal rico em metais e reciclável, aplicável a uma gama alargada de metais tóxicos, perturbação ambiental mínima, eliminação de produção de resíduos secundários gasosos ou líquidos que outros métodos envolvem, para além de fácil ou melhor aceitação pública [3].

Apesar da pesquisa sobre o processo de fito-extracção estar ainda numa fase embrionária, ensaios de campo em pequena escala, envolvendo plantas acumuladoras de metais, colhidas em locais contaminados, demonstraram a sua exequibilidade. Nesta perspectiva Baker et al. [25] cultivaram plantas acumuladoras de $\mathrm{Zn}$ (Thlaspi caerulescens, Cochlearia pyrenaica e várias espécies do género Alyssum) em solos contaminados com metais pela aplicação continuada de lamas provenientes de Estações de Tratamento de Águas Residuais (ETAR). No entanto, apesar de terem demonstrado com este estudo que o processo é aplicável, verificaram que a planta com um maior potencial para acumulação de $\mathrm{Zn}$ identificada, a $T$. caerulescens, demoraria 13 a 14 anos de cultivo contínuo para baixar a concentração de $\mathrm{Zn}$ no solo de $444 \mathrm{mg} / \mathrm{kg}$ até $300 \mathrm{mg} / \mathrm{kg}$ (valor imposto pela Comissão das Comunidades Europeias em 1986). Isso verifica-se porque, infelizmente, a maioria das plantas acumuladoras de metais identificadas até ao momento são de crescimento lento, pequenas (produzem uma quantidade diminuta de biomassa) e/ou daninhas (no sentido de que podem provocar efeitos nocivos). Ernst [33] alerta exactamente para o mesmo problema, tendo conseguido demonstrar experimentalmente que os solos com uma contaminação muito grande em metais podiam ser revegetados utilizando plantas resistentes a metais, mas a sua capacidade de descontaminação é restrita devido ao seu baixo rendimento em biomassa. Por isso, muito do esforço para desenvolver a fito-extracção tem sido concentrado na identificação de culturas conhecidas, ou espécies com elas relacionadas, que possam acumular metais, enquanto produzem um elevado rendimento em biomassa como resposta a estratégias agrícolas bem estabelecidas. Uma atenção particular tem sido dada às culturas relacionadas com a família Brassicaceae (grupo a que pertencem as cou- ves) que têm ligação com muitas das plantas selvagens acumuladoras de metais conhecidas até ao momento. Assim, Kumar et al. [3] identificaram várias espécies da família das Brassicaceae, que constituem culturas com elevado rendimento em biomassa, que acumulam eficientemente $\mathrm{Pb}$ e outros metais pesados. Enquanto que todas as culturas de Brassicaceae testadas (B. nigra, B. oleracea, B. campestris, B. carinata, B. juncea, e $B$. napus) acumulavam chumbo, algumas estirpes de Brassica juncea (L.) mostraram uma grande capacidade de acumular $\mathrm{Pb}$ nas raízes e de o transportar para as folhas $(108,3 \mathrm{mg}$ $\mathrm{Pb} / \mathrm{g}$ peso seco nas raízes e $34,5 \mathrm{mg}$ $\mathrm{Pb} / \mathrm{g}$ peso seco nas folhas). A B. juncea mostrou também ser capaz de concentrar $\mathrm{Cr}, \mathrm{Cd}, \mathrm{Ni}, \mathrm{Zn}$, e $\mathrm{Cu}$ nas folhas. Salt et al. [11] em trabalho posterior, compararam as capacidades de acumulação de metais (Cd, $\mathrm{Cu}, \mathrm{Cr}, \mathrm{Ni}, \mathrm{Pb}$ e $\mathrm{Zn}$ ) nas folhas da $B$. juncea e da espécie acumuladora selvagem $T$. caerulescens cultivadas em circunstâncias idênticas. Para todos os metais, excepto o Cd, a razão da concentração do metal nos tecidos da planta em relação à concentração inicial do metal na solução de tratamento era maior para a $T$. caerulescens do que para a B. juncea. Esta comparação directa demonstrou a capacidade da $T$. caerulescens para acumular maiores quantidades de $\mathrm{Zn}$ e Ni nas suas folhas quando comparada com a $B$. juncea. No entanto, a B. juncea produz, pelo menos, 20 vezes mais biomassa do que a $T$. caerulescens em condições de campo. dando àquela a possibilidade de remover uma maior quantidade de metal numa única colheita. Brown et al. [26] demonstraram que a T. caerulescens, quando comparada com outras duas espécies de plantas, Silene vulgaris L. e Lycopersicon esculentum L. (tomateiro), é mais resistente a efeitos tóxicos de $\mathrm{Zn}$ e Cd, conseguindo transportar uma maior quantidade desses metais do solo para as suas folhas.

Várias estirpes de Pseudomonas e de Bacillus foram capazes de aumentar a quantidade total de Cd acumu- 
lado por plantas de $B$. juncea criadas em viveiro. Assim, povoando a rizosfera com esse tipo de microrganismos deve ser possível aumentar a absorção de metais pesados pela planta a partir dos solos durante o processo de fito-extracção [11].

Porém, a menos que sejam descobertas e empregues práticas agrícolas especiais, de forma a tornar os metais do solo mais disponíveis para a planta, espera-se que os coeficientes de fito-extracção para as plantas colhidas no campo sejam muito mais baixos do que os obtidos em trabalhos de laboratório, em que se adiciona o metal a estudar na solução nutritiva. Por exemplo, o $\mathrm{Pb}$ no solo liga-se a argilas e a matéria orgânica, encontrando-se também em inclusões na forma precipitada, o que torna uma fraç̧ão significativa de $\mathrm{Pb}$ indisponível para ser absorvida pelas raízes das plantas colhidas no campo [3].

\subsection{Fito-estabilização}

Uma planta adequada a um processo de fito-estabilização é aquela que, para além de tolerar elevadas concentrações de metais tóxicos no solo, é capaz de os tornar mais inofensivos por absorção através da raiz, precipitação ou redução. Para além disso, estas plantas devem concentrar pouco metal nas suas folhas, de forma a que o material colhido não tenha que ser tratado como resíduo perigoso [11]. Os solos muito poluídos por metais pesados, principalmente os que se encontram nas proximidades de indústrias de extracção de minérios, apresentam-se na maioria das vezes desprovidos de vegetação devido aos efeitos tóxicos dos metais, sendo presa fácil para os agentes erosivos, levando rapidamente à disseminação dos poluentes no ambiente circundante, por lixiviação das águas da chuva ou por intermédio do vento, que aumentam diariamente o raio de acção do agente de poluição [30]. Uma solução muito simples para a estabilização destas áreas muito contaminadas com metais seria a sua revegetação com espécies tolerantes, reduzindo a mobilidade dos metais pesados, e diminuindo por isso os riscos de uma maior degradação ambiental por lixiviação dos metais para águas superficiais e subterrâneas, para além do espalhamento de partículas pelo vento. $\mathrm{O}$ estabelecimento e manutenção de vegetação deve fazer parte dos planos de recuperação de zonas afectadas por poluição de indústrias de extraç̧ão de minérios. No entanto, para que tal seja possível, é necessário conhecer muito bem os constrangimentos físico-químicos e biológicos ao crescimento das plantas, de forma a poder tornar possível o seu desenvolvimento nesses solos. De facto, estes possuem características muito adversas ao crescimento de plantas no que se refere a textura e estrutura, capacidade de retenção de água, estado nutritivo, $\mathrm{pH}$, existência de metais tóxicos em elevadas concentrações e salinidade [30]. Por isso, para que qualquer plano de fito-estabilização seja aplicável, é necessário em primeiro lugar efectuar um melhoramento das condições do solo a revegetar. A possibilidade de adição de lamas de ETAR, e também de produtos de compostagem de resíduos sólidos, a este tipo de solo tem sido muito estudada [34,35]. De facto, aquelas permitem melhorar as propriedades lísico-químicas dos solos por: (i) adição de nutrientes para o crescimento das plantas; (ii) aumento do teor em húmus e $\mathrm{pH}$; e (iii) aumento da capacidade de retenção de água. Verifica-se que os solos tratados com estas lamas possuem uma capacidade mais elevada para produção de biomassa vegetal do que os solos não tratados [35].

$\mathrm{O}$ recobrimento vegetativo deve ser feito, preferencialmente, com espécies endémicas, porque só essas possuem a necessária adaptação ao clima, para além de tolerância aos níveis de metais tóxicos existentes no local. Para a estabilização de zonas poluídas por escombreiras de minas na zona de Liverpool, na Grã-Bretanha, Smith et al. [36] utilizaram espécies vegetativas autóctones, resistentes aos metais. Utilizando técnicas de cultivo e fertilização adequadas, foram capazes de estabilizar o local, estabelecendo um excelente recobrimento vegetativo. Com base nestes estudos, encontram-se presentemente comercializadas em Inglaterra três variedades de gramíneas adaptadas a climas temperados: Agrostis tenuis (variedade Goginan) para solos ácidos com contaminação $\mathrm{Pb} / \mathrm{Zn}$, Festusca rubra (variedade Merlin) para solos calcários com contaminação $\mathrm{Pb} / \mathrm{Zn}$, e Agrostis tenuis (variedade Parys) para solos com contaminação por Cu [30]. No entanto, existe uma grande necessidade de descobrir espécies vegetais capazes de resistir a climas tropicais, sub-tropicais e áridos, em que as espécies mencionadas não crescem convenientemente.

De Koe [37] analisou os teores em metais pesados e arsénio nos solos e plantas (Agrostis castellana e Agrostis delicatula) de 15 locais próximos de minas, no Noroeste de Portugal. A partir deste estudo verificou que estas eram espécies resistentes a elevadas concentrações de metais pesados e arsénio, adequadas para planos de revegetação a desenvolver naquela zona do País. Os autores deste artigo iniciaram os estudos preliminares com a espécie autóctone Cistus lanadifer (L.) na zona das minas de Aljustrel. Estes estudos mostraram o carácter acumulador em relação ao $\mathrm{Mn}$, indicadora em relação ao $\mathrm{Zn}$ e resistente em relação ao $\mathrm{Cu}$ e ao $\mathrm{Pb}$ [38].

\subsection{Rizofiltração}

Uma planta ideal para o processo de rizofiltração deve ser capaz de acumular metais a partir de efluentes poluídos e por isso deve possuir raízes de crescimento muito rápido, que possuam a capacidade de remover metais tóxicos em solução durante largos períodos de tempo. Estudos recentes de Salt et al. [11], utilizando plantas com "raízes longas", demonstraram que muitas destas plantas possuem a capacidade intrínseca de absorver e precipitar metais pesados a partir da solução. 
Deste modo verificaram que, num período de 24 horas, raízes de girassol (Helianthus annuus L.) foram capazes de reduzir drasticamente os níveis de $\mathrm{Cr}, \mathrm{Mn}, \mathrm{Cd}, \mathrm{Ni}, \mathrm{U}, \mathrm{Pb}$, $\mathrm{Zn}$, Sr e Cu na água, levando as concentrações destes metais até, ou abaixo, dos valores limites regulamentados para descarga de águas residuais [11].

Os mecanismos de remoção dos metais tóxicos pelas raízes das plantas não são necessariamente semelhantes para os diferentes metais. No caso do $\mathrm{Pb}$, por exemplo, esses mecanismos de remoção podem ser divididos em três componentes principais. (1) A retenção à superfície da raiz é provavelmente a componente mais rápida da sua remoção. Essa retenção superficial é uma combinação de processos físico-químicos como sejam a quelação, permuta iónica e adsorção específica. Estes componentes não necessitam de actividade biológica e podem ter lugar em raízes mortas. (2) Os processos biológicos são responsáveis por uma componente mais lenta de remoção dos metais da solução. Estes processos biológicos incluem armazenamento intracelular, deposição em vacúolos e transporte para as folhas ${ }^{4}$. (3) $\mathrm{O}$ terceiro componente para a remoção de $\mathrm{Pb}$ de soluções concentradas, e também o mais lento, envolve a precipitação, mediada pela raiz, de $\mathrm{Pb}$ na forma de fosfatos insolúveis. Esta precipitação envolve, provavelmente, a libertação de exsudatos pela raiz. Por outro lado, as paredes celulares expostas ao chumbo acumulam grandes quantidades de $\mathrm{PbCO}_{3}$ insolúvel, formado a partir do $\mathrm{CO}_{2}$ da respiração. A combinação destes processos leva a uma cinética não-linear de desaparecimento do $\mathrm{Pb}$ da solução [11].

A rizofiltração é um processo eficiente e economicamente atractivo quando estão envolvidas baixas concentrações de contaminantes e elevados volumes de água. Neste caso, pode inclusive ser um processo útil quando se desejar tratar água contaminada com radionúclidos [11].

\section{CONCLUSÕES}

O desenvolvimento interactivo das áreas situadas entre a química e a botânica (ou a biologia, de uma forma geral) permitem uma leitura mais profunda de temas considerados classicamente como pertencentes apenas a esta última área científica [39]. Um melhor conhecimento dos processos metabólicos dos organismos vivos (em que as plantas estão incluídas) com os seus processos de captura, armazenamento, utilização e eliminação dos elementos químicos permitirá por exemplo encontrar soluções para o problema da contaminação de solos que normalmente têm sido objecto de abordagens demasiado simplistas as quais esquecem os múltiplos equilíbrios que estão em jogo nos processos naturais.

\section{AGRADECIMENTO}

Os autores agradecem:

- Ao Prof. J. J. R. Fraústo da Silva pelas sugestões e leitura crítica do manuscrito;

- Aos avaliadores anónimos deste manuscrito pelas suas sugestões que tornaram este trabalho mais claro $\mathrm{e}$ coerente.

\section{Escola Superior Agrária de Beja, \\ Praceta Rainha D. Leonor, 7800 Beja \\ 2 Departamento de Quimica, ITN - Instituto Tecno- lógico e Nuclear, EN 10, 2686 Sacavém CODEX \\ ${ }_{3}$ Centro de Química Estrutural, Instituto Superior Técnico, Av. Rovisco Pais 1, 1096 Lisboa CODEX}

+ Este trabalho corresponde a uma adaptação parcial da Tese de Mestrado de P. Alvarenga

1 Células suberizadas contêm suberina no seu exte rior, o que as torna impermeáveis a solutos aquosos.

2 Apoplasma: conjunto dos componentes nầo vivos da planta, compreendendo as paredes das células e os espaços intercelulares. O apoplasma constitui um contínuo que apenas sofre interrupção na endoderme da raiz [13].

3 Simplasma: conjunto do protoplasma, parte viva de todas as células da planta, limitado pela plasmalema, que forma um sistema contínuo devido às conexões citoplasmáticas intercelulares, plasmodesmata, que atravessam as paredes celulares [13].
4 O transporte de metais para as folhas tornam o processo de rizofiltração menos eficiente uma vez que produzem material vegetal contaminado. As plantas utilizadas em rizofiltração não devem por isso transportar metais eficientemente para as suas partes aéreas.

\section{BIBLIOGRAFIA}

1. D. A. Phipps, Chemistry and Biochemistry of Trace Metals in Biological Systems, in: Effect of Heavy Metal Pollution on Plants. (Pollution Monitoring Series) - Vol. 1: Effects of Trace Metal on Plant Function, N.W. Lepp (Editor), Applied Science Publishers, Essex, 1981.

2. E. Fieden, (Ed.) Biochemistry of the Essencial UItratrace Elements, Plenum Press, New York, 1984.

3. P. B. A. N. Kumar, V. Dushenkov, H. Motto, I. Raskin, Environmental Science \& Technology 29 (1995) 1232-1238.

4. B. E. Davies, L. H. P. Jones, Micronutrients and Toxic Elements, in: Russel's Soil Conditions \& Plant Growth, Alan Wild (Ed.), $11^{\text {th }}$ Edition, Longman Scientific \& Technical, USA, 1988, p: 780-814.

5. M. E. Farago, Metal lons and Plants, in: Frontiers in Bioinorganic Chemistry, A. V. Xavier (Ed.), VCH, Weinheim, 1986, p: 106-122.

6. E. J. Hewitt, T. A. Smith, Plant Mineral Nutrition. English University Press, London, 1975.

7. S. M. Ross, Sources and Forms of Potentially Toxic Metals in Soil-Plant Systems, in: Toxic Metals in Soil-Plant Systems, S. M. Ross (Ed.), John Wiley \& Sons, West Sussex, 1994, p: 3-25.

8. D. J. F. Bowling, Uptake of lons by Plant Roots, Chapman and Hall, London, 1976.

9. J. J. R. Fraústo da Silva, R. J. P. Williams, Structure and Bonding 29 (1976) 67-121.

10. L. H. P. Jones, S. C. Jarvis, The Fate of Heavy Metals, in: The Chemistry of Soil Processes, D. J. Greenland \& M. H. B. Hayes, John Wiley \& Sons, 1981, p: 593-620.

11. D. Salt, M. Blaylock, N. P. B. A. Kumar, V. Dushenkov, B. D. Ensley, 1. Chet, 1. Raskin, Bio/Technology 13 (1995) 468-474.

12. E. Epstein, Mineral Nutrition in Plants: Principles and Perspectives, Wiley, London, 1972.

13. I. Moreira, Histologia Vegetal, $3^{a}$ Ediçâo, Didáctica Editora, Lisboa, 1983.

14. R. G. Turner, Tese de Doutoramento, Universidade de Gales, Cardiff, 1967.

15. S. M. Ross, K. J. Kaye, The Meaning of Metal Toxicity in Soil-Plant Systems, in: Toxic Metals in Soil-Plant Systems, S. M. Ross (Ed.), John Wiley \& Sons, West Sussex, 1994, p: 27-61. 
16. M. E. Farago, X. Xiao, M. Cole, M. C. Vaz, Chemical Speciation and Bioavailability 4 (1992) 19-27.

17. S. Chaberek, A. E. Martell, Organic Sequestering Agents, John Wiley \& Sons, Inc. New York, 1959.

18. J. W. Huang, S. D. Cunningham, New Phytologyst 134 (1996) 75-84

19. E.-I. Ochiai, Journal of Chemical Education 72 (1995) 479-484.

20. A. Brookes, J. C. Collins, D. A. Thurman, Journal of Plant Nutrition 3 (1981) 695-705.

21. B. A. K. von Frenckell-Insam, T. C. Hutchinson, New Phytologyst 125 (1993) 555-564.

22. A. J. M. Baker, Journal of Plant Nutrition 3 (1981) 643 .

23. R. R. Brooks, J. Lee, R. D. Reeves, T. Jaffre, Journal of Geochemical Exploration 7 (1977) 49-57.

24. U. Krämer, J. D. Cotter-Howells, J. M. Charnock, A. J. M. Baker, J. A. C. Smith, Nature 379 (1996) 635-638

25. A. J. M. Baker, S. P. McGrath, C. M. D. Sidoli, R. D. Reeves, Resources, Conservation and Recycling 11 (1994) 41-49.
26. S. L. Brown, R. L. Chaney, J. S. Angle, A. J. M. Baker, Journal of Environmental Quality 23 (1994) 1151-1157

27. A. Varennes, M. O. Torres, J. F. Coutinho, M. M. G. S. Rocha, M. M. P. M. Neto, Journal of Plant Nutrition 19 (1996) 669-676.

28. I. Vágó, Z. Gyóri, J. Loch, Fresenius Journal of Analytical Chemistry 354 (1996) 714-717.

29. S. N. Martens, R. S. Boyd, Oecologia 98 (1994) 379-384.

30. A. Williamson, M. S. Johnson, Reclamation of Metalliferous Mine Wastes, in: Effect of Heavy Metal Pollution on Plants. (Pollution Monitoring Series) - Vol. 2: Metals In The Environment, N. W. Lepp (Ed.), Applied Science Publishers, Essex, 1981.

31. A. Aksoy, M. Ozturk, Journal of Trace and Microprobe Techniques, Soil and Environmental Sciences 14 (1996) 605-614.

32. S. M. Al-Shayeb, M. A. Al-Rajhi, M. R. D. Seaward, The Science of the Total Environment $\mathbf{1 6 8}$ (1995) 1-10.

33. W. H. O. Ernst, Applied Geochemistry 11 (1996) 163-167.

34. J. R. Pichtel, W. A. Dick, Journal of Environ- mental Quality 23 (1994) 766-772.

35. C. S. Rodgers, R. C. Anderson, Journal of Environmental Quality 24 (1995) 627-630.

36. R. A. H. Smith, A. D. Bradshaw, Journal of Applied Ecology 16 (1979) 595-612.

37. T. De Koe, The Science of the Total Environment 145 (1994) 103-109.

38. P. Alvarenga, Tese de Mestrado, Universidade de Évora, 1997

39. J. J. R. Fraústo da Silva, R. J. P. Williams, The Biological Chemistry of the Elements - The Inorganic Chemistry of Life, Clarendon Press, Oxford, 1991.

\section{A propósito:}

A árvore das patacas:

Investigadores neo-zelandeses mostraram recentemente que algumas plantas podiam extrair ouro do solo (C.W.N. Anderson et al., Nature, 395, 553, 1998). Conseguiram multiplicar a eficácia da absorção natural através da utilização de Tiocianato de amónio que solubiliza o metal. A mostarda branca (Brassica juncea) pode assim conter até 57 microgramas de ouro por grama deplanta seca..

\section{CERTIFICADO DE CONFORMIDADE}

Instituto Português da Qualidade

\section{O INSTITUTO PORTUGUÊS DA QUALIDADE certifica que o Sistema} da Qualidade da

\section{SOQUÍMICA - SOCIEDADE DE REPRESENTAÇÕES DE}

\section{QUIMICA, LDA.}

Rua Coronel Santos Pedroso, 15

1500 LISBOA

PORTUGAL

implantado na comercialização, manutenção e calibração de equipamentos de laboratório, cumpre os requisitos da Norma Portuguesa NP EN ISO 9002 - "Sistemas da Qualidade. Modelo de garantia da qualidade na produção, instalação e assistência após venda".

O presente certificado é emitido ao abrigo do Decreto-Lei n. ${ }^{\circ} 234 / 93$ de 2 de Julho, e de acordo com a Directiva CNQ 22 - "Certificação de sistemas da qualidade de empresas. Metodologias e regras gerais".

A presente certificação é válida por um periodo de três anos, renovável.

Monte de Caparica, 18 de Junho de 1996

\section{Caüdíd do Sauton}

Cândido dos Santos

Presidente

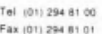
NUMERO

96/CEP.410

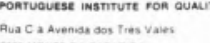

